University of Northern lowa

UNI ScholarWorks

\title{
The influence of gain-loss framing and its interaction with political ideology on social distancing and mask wearing compliance during the COVID-19 pandemic
}

Jordan Steffen

University of Northern lowa

Let us know how access to this document benefits you

Copyright @2021 Jordan Steffen

Follow this and additional works at: https://scholarworks.uni.edu/hpt

\section{Recommended Citation}

Steffen, Jordan, "The influence of gain-loss framing and its interaction with political ideology on social distancing and mask wearing compliance during the COVID-19 pandemic" (2021). Honors Program Theses. 493.

https://scholarworks.uni.edu/hpt/493

This Open Access Honors Program Thesis is brought to you for free and open access by the Student Work at UNI ScholarWorks. It has been accepted for inclusion in Honors Program Theses by an authorized administrator of UNI ScholarWorks. For more information, please contact scholarworks@uni.edu. 
THE INFLUENCE OF GAIN-LOSS FRAMING AND ITS INTERACTION WITH POLITICAL IDEOLOGY ON SOCIAL DISTANCING AND MASK WEARING COMPLIANCE DURING THE COVID-19 PANDEMIC

\author{
A Thesis Submitted \\ in Partial Fulfillment \\ of the Requirements for the Designation of \\ University Honors
}

Jordan Steffen

University of Northern Iowa

May 2021 
This Study by: Jordan Steffen

Entitled: The Influence of Gain-Loss Framing and Its Interaction with Political Ideology on Social Distancing and Mask Wearing Compliance During the COVID-19 Pandemic

has been approved as meeting the thesis requirements for the Designation of University Honors

$\underline{04 / 28 / 2021}$

Date

Date
Dr. Jiuqing Cheng

Dr. Jiuqing Cheng, Honors Thesis Advisor, Psychology Department

Dr. Jessica Moon, Director, University Honors Program 


\begin{abstract}
The COVID-19 pandemic has caused millions of cases and over half a million deaths in the United States. While health experts urge citizens to adopt preventative measures such as social distancing and wearing a mask, these recommended behaviors are not always followed by the public. To find a way to promote preventative measures, the present study examined the role of gain-loss framing of COVID-19 related messages on social distancing and mask wearing compliance. Moreover, the study also tested potential moderating effects on framing with three individual characteristics: political ideology, subjective numeracy, and risk attitude. A sample of 375 U.S. adult residents were recruited from Amazon Mechanical Turk. Each participant read either a gain or loss-framed message related to practicing protective behaviors during the COVID-19 pandemic. Participants also completed scales of preventative behaviors, risk attitude, subjective numeracy, political ideology, and other demographic variables. It was found that those who were liberal, risk-averse and had greater subjective numeracy were more likely to wear a mask and/or follow social distancing. Furthermore, in the presence of demographic and psychological factors, the study found participants in the loss-framed condition than in the gainframed condition were more likely to adopt both preventative measures, supporting the notion of loss aversion. Additionally, the framing effect was also moderated by political ideology on mask-wearing, with the effect being stronger in liberals than in conservatives. Collectively, the study implies message framing may be a useful means to promote preventative measures in the current pandemic.
\end{abstract}

Key words: COVID-19, mask wearing, social distancing, framing effect, risk attitude, political ideology, subjective numeracy 


\section{Introduction}

The SARS-CoV-2 virus has created one of the deadliest pandemics in history. The World Health Organization (WHO) declared the coronavirus disease a pandemic on March 11th, 2020 (Shah et al., 2020). After only 8 months, as of November 3rd, 2020, there have been about 9.2 million COVID-19 cases and over 230,000 reported deaths in the United States (Jennings, 2020). Health experts say that social distancing and wearing a mask are two of the most important preventative measures one can take to slow the spread of the infectious disease (Leung et al., 2020). However, these recommended behaviors are not always followed by the public. Not following social distancing guidelines is common (De Witte, 2020), while the use of face masks has been controversial and even highly politicized (Kahane, 2021). Therefore, it is imperative to find a way to promote these preventative measures.

The primary goal of this study was to examine the effect of message framing on the behaviors of social distancing compliance and mask-wearing. Past research has found message framing could promote a variety of health behaviors (e.g., Rothman et al., 1993; Yang, 2018). Compared to other strategies such as educating thinking disposition and self-control $(\mathrm{Xu} \&$ Cheng, 2021), framing can be operated more efficiently. Thus, the present study aimed to further extend the work of framing to the preventative behaviors in the current pandemic. Moreover, to understand the framing effect in the COVID-19 pandemic more comprehensively, this study also attempted to identify potential variables (e.g., political ideology) that may moderate the effect of message framing.

\section{Framing effect and the COVID-19 pandemic}

Framing refers to how a message or question is presented to its audience. Often, the context of the message is not what matters most, but how it is said has the biggest impact 
(Ogbodo, 2020). The concept of message framing is an important aspect in health

communication. The design of a message has the potential to alter an individual's perception of the message content and can therefore influence their behavior and attitude towards the subject (Fetter et al., 2019). Following past research (e.g., Fetter et al., 2019; Tversky \& Kahneman, 1981), the present study employed gain-loss framing, a popular framing paradigm, to examine the effect it has on preventative behaviors. Gain and loss framing specifically tap into emotional responses to messages (Tversky \& Kahneman, 1981). Gain frames are typically positive and emphasize benefits while loss frames lean more negative and emphasize costs of a particular decision (Holton, 2014). An example of gain and loss-framed messages that were used in an Obesity-prevention program from Fetter et al. (2019) include "exercising regularly can help you lose weight” (gain) versus “not exercising regularly can make you gain weight” (loss).

A few studies have applied the gain-loss framing in the context of the COVID-19 pandemic. ${ }^{1}$ In Hameleers (2020), participants chose hypothetical risk-averse or risk-seeking treatment programs when such programs were gain and loss framed. Specifically, in the gain condition, the risk-averse program was $65 \%$ of all contaminated people can be saved whereas the risk-seeking program was $65 \%$ likelihood to save all contaminated people, and a 35\% likelihood to save none of the contaminated people. In the loss condition, the programs adopted equivalent statistics but were presented with loss terms: $35 \%$ of all contaminated people will die (risk-averse) vs. a $65 \%$ likelihood that none of the contaminated people will die, and a $35 \%$ likelihood that all of the contaminated people will die (risk-seeking). Consistent with the notion of the Prospect Theory, the model showing how people decide between alternatives involving risk and uncertainty (Tversky \& Kahneman, 1979), the present study found that the risk-averse

\footnotetext{
${ }^{1}$ Jordan et al. (2020) and Palm et al. (2021) also tested the framing effect on behaviors and attitudes in the COVID19 Pandemic. However, these studies did not specifically employ the gain-loss framing.
} 
program was more favorable in the gain condition, whereas as the risk-seeking program was more preferred in the loss condition.

In another study on framing and the pandemic (Sanders et al., 2021), the authors framed the projected number of deaths in the United Kingdom (As many as 100,000 people could be saved by a well-managed extension to the lockdown vs. As many as 100,000 people could die without a well-managed extension to the lockdown) and asked participants to report their views on lockdown and intention to adhere public health guidelines. However, the study did not find any significant framing effect. By contrast, Gantiva et al. (2021) expressed the self-care behaviors (hand washing, physical distance, and staying home) with a gain-loss framing manipulation and discovered that the gain-framed message was more effective in promoting such behaviors in residents in Columbia.

Given the inconclusive results from the past research, the present study aims to continue examining how framing can be used to promote health behaviors in the current pandemic. Due to the crucial role of mask-wearing and social distancing compliance in mitigating virus spread, the current work chooses to test the effect of gain-loss framing on these behaviors.

\section{Potential moderators: political ideology, subjective numeracy, and risk attitude}

While framing itself may change behaviors, past research has shown framing is subject to moderating effect. Thus, to depict the framing effect more precisely, the present study tests a few potential moderators. These moderators are common individual characteristics and were chosen based on two reasons. First, previous studies have found that these individual characteristics could moderate the effect of message framing. Second and more importantly, the potential moderators are closely related to behavioral and mental processes in the COVID-19 pandemic. 
Political ideology. Political ideology is how someone identifies themselves on a spectrum, usually from having conservative (Republican-leaning) views to having liberal (Democratic-leaning) views. Framing may be moderated by political ideology. For instance, in a study where participants were asked to evaluate crime-reduction proposals, the effect of crimerelated information framing (metaphorize crime as a beast vs. a virus) was moderated by political ideology, with Republicans showing less sensitivity to the framing effect (Thibodeau \& Boroditsky, 2011). Furthermore, in the COVID-19 pandemic, political ideology has played a prominent role in health behaviors. For example, the results from a Gallup poll suggested that Democrats and Independents continuously see COVID-19 as a deadly virus. On the other hand, Republicans are 10 times more likely as Democrats to say the death count is overstated (Ritter, 2020). Ramos et al. (2020) argued that the difference in attitudes towards taking these preventative measures are due to the fundamental differences in normative principles and belief systems reflected by one's political ideology. Consistent with this notion, Xu and Cheng (2021) found that a more liberal view was related to a greater tendency to wear a mask and follow social distancing. In the same study, political ideology also moderated the positive effect of need for cognition and self-control on mask-wearing behavior, with the effect being more prominent in liberals than in conservatives. Together, given the powerful impact of political ideology in the current pandemic, the present study aims to empirically test whether political ideology moderates the framing effect on preventative measures. Following the studies described above, we predict that the framing effect was stronger in more liberal participants than in more conservative participants.

Subjective numeracy. Greater numeracy has been found to be associated with making more advantageous decisions (the numeracy hypothesis raised in Sinayev \& Peters, 2015). For 
example, higher numerate participants were more likely to select the later larger gains over the sooner smaller gains in intertemporal choices (Cheng, 2020). In health and medication-related decisions, higher numerate participants, as opposed to lower counterparts, were more likely to identify and select the best possible treatment (Reyna et al., 2009). In the pandemic, the public constantly receives numerical messages such as the number of positive cases and deaths, positivity rate, and projected cases in varying scenarios (e.g., with or without lockdown). Thus, how people comprehend and utilize numerical information may affect their choices on preventative measures. Moreover, past research has found that greater numeracy has been associated with reduced susceptibility to the framing effect (Peters \& Levin, 2008; Peters, 2012), possibly because higher numerate participants were more likely to capture the gist of the message. Thus, the present study aims to examine whether numeracy also moderates the framing effect on preventative behaviors in this pandemic.

It is worth noting that past research mainly tested objective numeracy. To advance the understanding of numeracy, the present study employs subjective numeracy (Fagerlin et al., 2007). Subjective numeracy pertains to the willingness and motivation to utilize numerical information, whereas objective numeracy taps into the actual operations (Peters \& Bjalkebring, 2015). Despite the conceptual difference, some studies found these two types of numeracy had a similar correlation with gamble choice, intertemporal choice, and how the public perceived the police (Cheng, 2020; Peters \& Bjalkebring, 2015; Pham \& Cheng, 2020). Taken together, following the numeracy hypothesis and the studies described above, we predict that subjective numeracy is positively associated with the behaviors of social distancing and mask-wearing. Additionally, we also predict that people with greater subjective numeracy are less susceptible to the framing effect. 
Risk attitude. Risk attitude is closely related to health behaviors. For example, riskaverse (as opposed to risk-seeking) students on a college campus were less likely to engage in risky sexual behaviors that may result in STDs and unwanted pregnancies (Whyte et al., 2017). As the pandemic poses a great risk on well-being, how people respond to risk may affect their relevant behaviors. For example, studies found that greater risk-averse (as opposed to riskseeking) was related to a reduction of human mobility and travel intention (Chan et al., 2020; Luo \& Lam, 2020), and to more social distancing and mask-wearing (Miguel et al., 2021; Xu \& Cheng, 2021). Compared to those studies, the current study was performed at a later stage when the situation had largely changed (e.g., the U.S. election had been held and the initial promising vaccine results had been released to the public). However, given risk attitude is an intrinsic propensity, we expect to replicate the role of risk attitude in the present study: greater risk-averse is related to more preventative behaviors.

Furthermore, a recent study found risk attitude could influence the framing effect, with participants with a higher risk-seeking tendency (i.e., lower risk-averse tendency) being less prone to the gain-loss framing (Tabesh et al., 2019). As noted in the article, a possible reason was that a strong risk-seeking propensity (i.e., greater willingness to take an action) might dominate the situational uncertainties (i.e., different frames) and thus, people with such a propensity were less likely to be influenced by positive or negative situational contexts. Following this, the present study empirically tests the potential interaction between risk attitude and framing. Additionally, past research has shown risk attitude varies along with age, with older adults being more risk-averse than their counterparts (Best \& Charness, 2016; Mather et al., 2013). More importantly, the current pandemic poses a significantly higher risk to older adults. For example, according to CDC (Centers for Disease Control and Prevention, 2021), the risk for 
hospitalization, severe illness and death caused by COVID-19 increases with age, with older adults at highest risk. Thus, in addition to the framing effect, we also test the interaction between risk attitude and age. Given the higher risk that older adults encounter in the current pandemic, we predict that risk attitude may play a more prominent role in older adults with regards to preventative behaviors.

\section{Overview}

Inspired by the work done by Tversky and Kahneman, the framing effect has been popular in the domain of health communication. Following past research, the present study aims to examine whether message framing can affect the behaviors of mask-wearing and social distancing. These two behaviors are crucial preventative measures to protect individuals and mitigate virus spread, especially when vaccination is still in progress. Furthermore, the study also tests three important individual characteristics that might moderate the effect of framing. Together, we hope to elucidate the role of framing in the context of the COVID-19 pandemic, along with identifying relevant psychological and demographic factors that are critical to preventative measures.

\section{Methods}

\section{Participants}

The study was approved by IRB before data collection. Participants were recruited from Amazon Mechanical Turk (mTurk) on November $11^{\text {th }}, 2020$. To be eligible for the study, participants must be an adult, a U.S. resident, and have an approval rating greater than $98 \%$ in mTurk. A total of 375 participants were enrolled into the study. Each participant received $\$ 1.00$ for their time. Demographics are found in the results section. To estimate the effect size that could be detected with the current sample size, a sensitivity analysis was conducted with 
$\mathrm{G}^{*}$ Power 3.1.9. With $\alpha=.05$ and power $=.80$, the sample size allowed to detect an $R^{2}$ as low as .05 in a linear regression reported below.

\section{Materials and Procedures}

Participants took an online survey via Qualtrics. The following questionnaires were completed in the following order:

Risk attitude scale. The present study employed the health/safety subscale of the Domain Specific Risk-Taking Scale (DOSPERT, Blais \& Weber, 2006) to measure risk attitude (risk seeking vs. risk averse). ${ }^{2}$ The subscale contains six items (e.g., Driving a car without a seat belt) and assesses risk attitude regarding behaviors and actions in the health and safety domains. Participants evaluated the likelihood of engaging in a potentially risky action or behavior with a 7-point Likert rating scale, with 1 as extremely likely and 7 as extremely unlikely. An average was taken across the six items, with a higher score indicating a higher level of risk averse (or a lower tendency to engage in risky behaviors). The reliability for the scale was .74.

Subjective Numeracy Scale. The Subject Numeracy Scale (SNS, Fagerlin et al., 2007) was used to measure the perceived ability to perform various mathematical tasks and preference for the use of numerical information. The scale consists of 8 items. Example items include: “How good are you at working with percentages?”. Each item was responded with a 7-point Likert rating scale, ranging from 1= Not at all good/helpful to 7= Extremely good/Always prefer. One item was reverse coded: "How often do you find numerical information to be useful?" using the scale $1=$ Never to $7=$ Very often. An average was taken across the entire scale, with a larger score indicating greater subjective numeracy. The reliability of the scale was .74.

\footnotetext{
${ }^{2}$ Blais \& Weber (2006) suggested users should adopt different subscales depending on the testing domain. Following this, the present study adopts the health/safety subscale to represent risk attitude.
} 
Demographic variables. After completing the scales presented above, participants were asked to report their demographic information including race, age, gender identity, annual household income, education, and political ideology.

Race was coded with $1=$ White or Caucasian, $2=$ Hispanic or Latinx, $3=$ Black or African American, $4=$ Asian or Asian American, and $5=$ Other. Gender was coded with $1=$ Male, $2=$ Female, and $3=$ Other. Annual household income was measured with seven levels and ranged between under $\$ 9,999$ and above $\$ 150,000$ with various increments (details see results). Education was coded with six levels: $1=$ Less than high school graduate, $2=$ High school graduate or equivalent, $3=$ Some college or associate degree, $4=$ Bachelor's degree, $5=$ Master's degree, $6=$ Doctoral degree.

Political ideology was calculated by asking participants to rate four items from 1 (Very conservative) to 5 (Very liberal). The four items included: overall political orientation, views on social issues, views on economic issues, and views on foreign policy (Inbar \& Lammers, 2012). An average was taken across the items, with a high score indicating a more liberal ideology. The reliability of the political ideology scale was .89 .

Gain and loss framed messages. Participants were randomly assigned to read a message presented in either a gain or loss frame. The gain framed message was positive and highlighted the number of potential lives saved, while the loss framed message was negative and highlighted the number of potential lives lost. Each message began with a piece of background information regarding the projection of Covid-19 related deaths: "The Institute for Health Metrics and Evaluation (IHME) is an independent global health research center at the University of Washington. IHME has created COVID-19 projections that include a variety of forecasts, including cumulative COVID-19 deaths in the United States through the 1st of February, 2021". 
The gain framed message followed with: "Health experts are saying that taking preventative measures such as social distancing and wearing a mask could save 130,000 lives between now and February 1st, 2021 in the United States". The loss framed message followed with: "Health experts are saying that without practicing preventative measures such as social distancing and wearing a mask, 1300,000 people could die between now and February 1st, 2021 in the United States".

Mask-wearing behavior. After reading the message, participants were asked to rate how they would behave in regards to mask-wearing in the next month. The future mask-wearing behavior question asked: "Based on the previous statement about taking preventative measures, will you wear a mask when going out in public in the next month?" Participants responded with a Likert scale with $1=$ Never and 7= Always.

Social distancing compliance. Following Xie et al., (2020) and $\mathrm{Xu}$ and Cheng (2021), participants were asked how they would behave in regards to social distancing in the next month. The future social distancing behavior questions asked were (1) will go to church or attend other community activities; (2) will give handshakes, hugs or kisses when greeting; (3) will hold social gathering with friends; (4) will keep at least 6 feet from other people who are not from your household in both indoor and outdoor spaces; and (5) will go to events or gatherings. Participants responded with a Likert scale with $1=$ Never and 7= Always (the fourth item was reverse coded). An average was taken across the five items with a lower score indicating a stronger tendency for future social distancing compliance. The reliability of this scale was .86.

\section{Data analysis}

SPSS 24.0 was employed to run the analyses reported below. In addition to the descriptive statistics and zero-order correlations, hierarchical linear regressions were performed 
to exhibit the effect of frame, risk attitude and other variables on mask-wearing and social distancing, respectively. In each regression, age, gender, education, income, political ideology, subjective numeracy, risk attitude and frame entered the first block. In the second block, the interactions of frame*political ideology, frame*subjective numeracy, frame*risk attitude, and risk attitude*age were further added. In regressions, the variables of frame were dummy coded. The variables of political ideology, age, risk attitude, and subjective numeracy were mean centered.

\section{Results}

Across 375 participants, there were $232(61.9 \%)$ of males and 143 females. None selected other as gender. Age ranged between 21 and 69, with a mean of $34.73(S D=10.92)$. Political ideology ranged between 1 and 5 (most liberal), with a mean of $3.35(S D=1.03)$. Table 1 presents the information of education, income, and race.

Table 1 Descriptive statistics for race, education, and income

\begin{tabular}{llll}
\hline Variable & Category & Frequency & Percentage (\%) \\
\hline Education & Less than high school graduate & 0 & 0 \\
& High school graduate or equivalent & 35 & 9.3 \\
& Some college or associate degree & 46 & 12.3 \\
& Bachelor's degree & 227 & 60.5 \\
& Master's degree & 65 & 17.3 \\
Income (\$) & Doctoral degree & 2 & .5 \\
& Under 9999 & 17 & 4.5 \\
& $10,000-24,999$ & 41 & 10.9 \\
& $25,000-49,999$ & 92 & 24.5 \\
& $50,000-74,999$ & 131 & 34.9 \\
Race & $75,000-99,999$ & 60 & 16.0 \\
& $100,000-149,999$ & 29 & 7.7 \\
& Over 150,000 & 5 & 1.3 \\
& White or Caucasian & 282 & 75.4 \\
& Hispanic or Latinx & 10 & 2.7 \\
& Black or African American & 34 & 9.1 \\
& Asian or Asian American & 47 & 12.6 \\
& Other & 1 & .3 \\
\hline
\end{tabular}


Table 2 presents the descriptive statistics of behavioral measures, including maskwearing, social distancing, subjective numeracy, and risk attitude. Table 2 Descriptive statistics of behavioral measures

\begin{tabular}{llccl}
\hline Variable & MW & SDC & SNS & HSRA \\
\hline Mean & 5.77 & 3.59 & 4.39 & 4.84 \\
SD & 1.28 & 1.58 & .71 & 1.01 \\
Minimum & 1 & 1 & 1.88 & 1.83 \\
Maximum & 7 & 7 & 6 & 7 \\
\hline
\end{tabular}

MW: mask-wearing behavior; SDC: social distancing compliance; SNS: subjective numeracy; HSRA: health/safety risk attitude

Table 3 exhibits the zero-correlations between mask-wearing, social distancing compliance, framing, and other variables of interest. Mask-wearing and social distancing were moderately correlated, indicating while they were both protective behaviors; however, they tapped into different constructs and people might have varied views on them. The correlations displayed some initial evidence of framing. That is, compared to the gain condition, participants showed greater willingness to wear a mask and follow social distancing in the loss condition. Such a pattern was in line with the notion of loss aversion. Consistent with Miguel et al. (2021) and $\mathrm{Xu}$ and Cheng (2021), intention to wear a mask was related to a greater risk averse attitude and a more liberal political ideology. Political ideology was also related to social distancing compliance. Additionally, a stronger subjective numeracy was associated with greater willingness to wear a mask but not following social distancing. Interestingly, more education correlated with less social distancing. A possible reason might be those with a higher level of education better understood social interaction as a basic human need (Sikali, 2020) and were used to having social experiences (e.g., college activities). Hence, it might be more difficult for these people to maintain social distancing. 
Table 3 Correlations between mask-wearing, social distancing compliance, framing and other variables

\begin{tabular}{|c|c|c|c|c|c|c|c|c|c|}
\hline & SDC & Frame & HSRA & SNS & PI & Age & Gend & Inc & Edu \\
\hline MW & $-.39^{* * * *}$ & $.20^{* * * *}$ & $.28^{* *}$ & $.25^{* * * *}$ & $.25^{* * *}$ & .06 & -.05 & $.13^{*}$ & -.02 \\
\hline SDC & & $-.11^{*}$ & -.04 & -.09 & $-.11^{*}$ & $-.17^{* *}$ & -.03 & -.05 & $.33^{* * * *}$ \\
\hline Frame & & & .04 & .06 & .07 & -.04 & -.07 & $.12^{*}$ & .04 \\
\hline HSRA & & & & $.24^{* * * *}$ & $.12^{*}$ & -.07 & $.13^{*}$ & .08 & .09 \\
\hline SNS & & & & & .07 & $.17^{* *}$ & .003 & .09 & $.12^{*}$ \\
\hline PI & & & & & & $-.18^{* *}$ & -.01 & -.05 & .01 \\
\hline Age & & & & & & & $.14^{* *}$ & $-.14^{* *}$ & $-.15^{* *}$ \\
\hline Gend & & & & & & & & -.03 & -.04 \\
\hline Inc & & & & & & & & & $.29^{* * * *}$ \\
\hline
\end{tabular}

MW: mask-wearing behavior; SDC: social distancing compliance; Frame: 1 = gain, 2 = loss; HSRA: health/safety risk attitude; SNS: subjective numeracy; PI: political ideology; Gend: gender, 1 = males, 2 = females; Inc: income; Edu: education. *: $p<.05 ; * *: p<.01 ; * * *: p<$ .001

Although correlations generated meaningful result, we were mindful that the chance of having a type I error might get inflated with multiple simultaneously correlations being performed. Hence, to further examine the effect of framing, risk attitude and other variables on mask-wearing and social distancing, we proceed to regressions. In particular, we were interested in testing potential interactions with regressions. Table 4 demonstrates the results of the hierarchical linear regressions. For the effect of individual variables on mask-wearing and social distancing, the results were similar between zero-order correlations and regressions (block 1). For instance, political ideology and framing manipulation associated with protective behaviors in both analyses. Beyond correlations, in block 2 of the hierarchical linear regressions, we tested interactions to specify the impact of moderating effect on framing. As a result, for mask-wearing, there was a significant interaction between framing and political ideology. Additionally, the interaction between risk attitude and age was significant for both mask-wearing and social distancing. 
Table 4 Hierarchical linear regressions on mask-wearing and social distancing compliance

\begin{tabular}{|c|c|c|}
\hline & Mask-wearing & Social distancing \\
\hline Blocks and Variables & $\mathrm{B}(\mathrm{SE})$ & $\mathrm{B}(\mathrm{SE})$ \\
\hline \multicolumn{3}{|l|}{ Block 1} \\
\hline$R^{2}$ Change & $.22^{* * *}$ & $.19^{* * * *}$ \\
\hline Age & $.01(.01)$ & $-.02(.01)^{* *}$ \\
\hline Gender & $-.21(.13)$ & $-.01(.16)$ \\
\hline Income & $.13(.05)^{*}$ & $-.21(.06)^{* *}$ \\
\hline Education & $-.15(.08)$ & $.71(.10)^{* * *}$ \\
\hline PI & $.28(.06)^{* * *}$ & $-.21(.08)^{* *}$ \\
\hline HSRA & $.26(.06)^{* * *}$ & $-.01(.08)$ \\
\hline SNS & $.29(.09)^{* *}$ & $-.15(.11)$ \\
\hline Framing & $.41(.12)^{* *}$ & $-.36(.15)^{*}$ \\
\hline \multicolumn{3}{|l|}{ Block 2} \\
\hline$R^{2}$ Change & $.03^{* *}$ & .01 \\
\hline Age & $.01(.01)$ & $-.02(.01)^{*}$ \\
\hline Gender & $-.23(.12)$ & $.003(.16)$ \\
\hline Income & $.13(.05)^{*}$ & $-.22(.06)^{* *}$ \\
\hline Education & $-.13(.08)$ & $.70(.01)^{* * *}$ \\
\hline PI & $.18(.08)^{*}$ & $-.20(.10)^{*}$ \\
\hline HSRA & $.30(.08)^{* * *}$ & $-.04(.11)$ \\
\hline SNS & $.46(.13)^{* * *}$ & $-.14(.17)$ \\
\hline Framing & $.43(.12)^{* * *}$ & $-.38(.15)^{*}$ \\
\hline Framing $\times$ PI & $.24(.12)^{*}$ & $-.04(.15)$ \\
\hline Framing $\times$ SNS & $-.28(.17)$ & $-.06(.22)$ \\
\hline Framing $\times$ HSRA & $-.11(.12)$ & $.08(.16)$ \\
\hline HSRA $\times$ Age & $.01(.005)^{*}$ & $-.01(.007)^{*}$ \\
\hline
\end{tabular}

Framing: 1 = gain, 2 = loss; HSRA: health/safety risk attitude; SNS: subjective numeracy; PI: political ideology. *: $p<.05 ; * *: p<.01 ; * * *: p<.001$.

To unpack the interactions, the variables of political ideology, risk attitude and age were divided into a high group and a low group with median split. Figures 1-3 depicts the specific pattern of the interactions. As shown in Figure 1, the framing effect (gain-loss asymmetry) appears to be more significant in the more liberal participants than in the more conservative participants. Previous research found political ideology moderated the effect of need for cognition and self-control on protective behaviors (Xu \& Cheng, 2021). The current work further extended the moderating role of political ideology to the framing effect. Figures 2 and 3 exhibit 
the interactions between risk attitude and age for mask-wearing and social distancing, respectively. For mask wearing, while risk averse was associated with greater mask-wearing in both age groups, such a pattern was more pronounced in the older participants than in the younger participants. For social distancing compliance, whereas the effect of risk averse was relatively stable in younger participants, risk averse was more related to greater social distancing compliance in older participants.

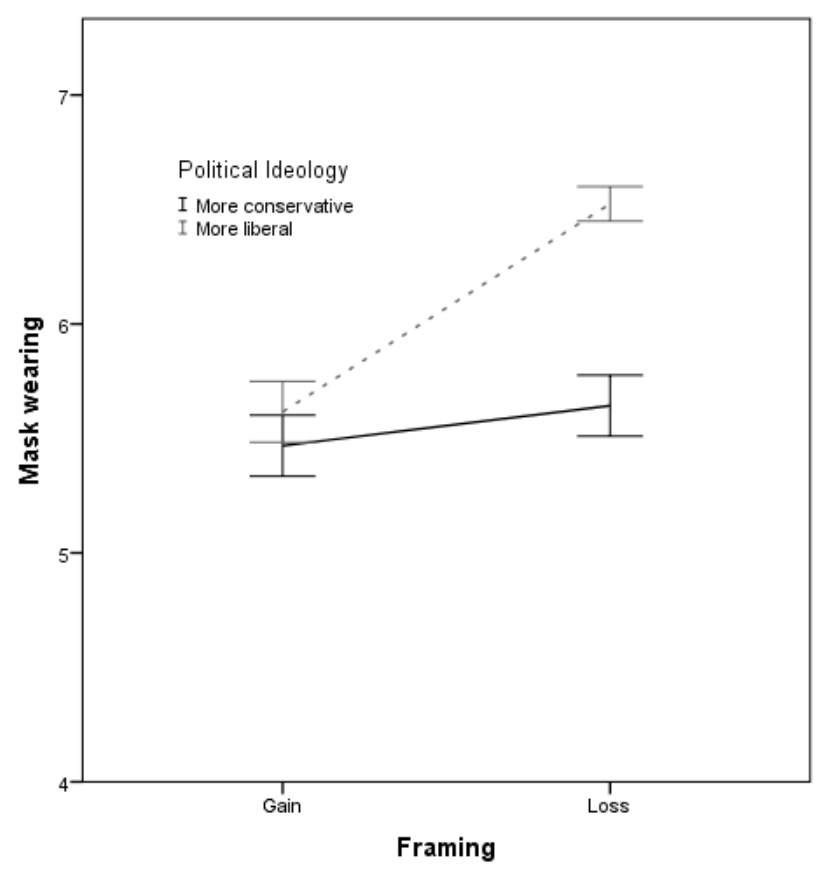

Figure 1. Interaction between framing and political ideology on mask wearing. 


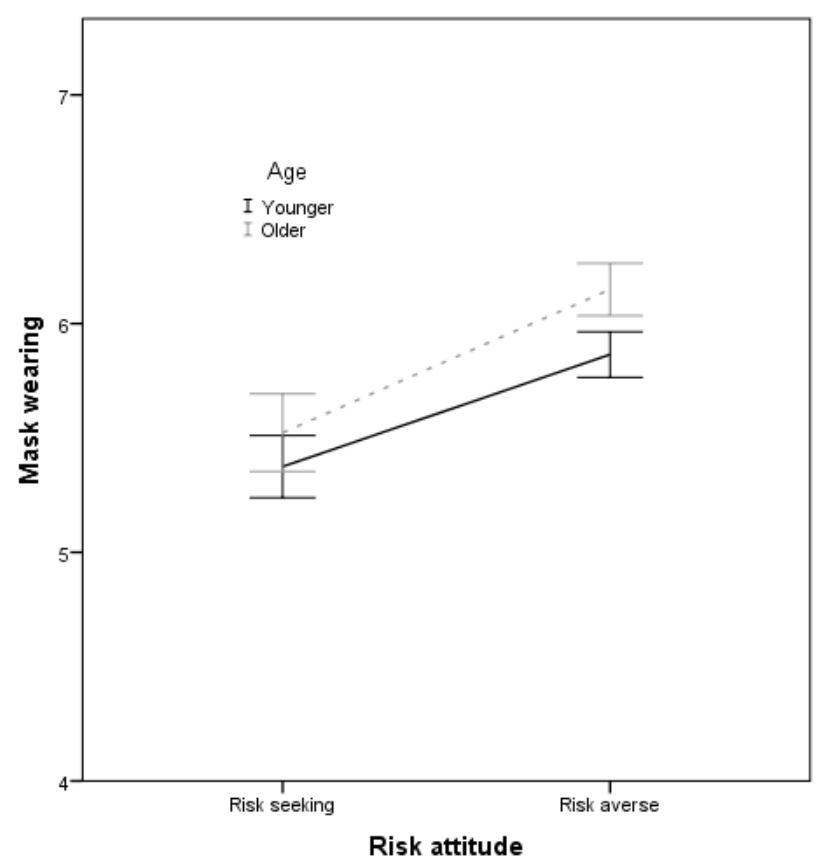

Figure 2. Interaction between risk attitude and age on mask wearing.

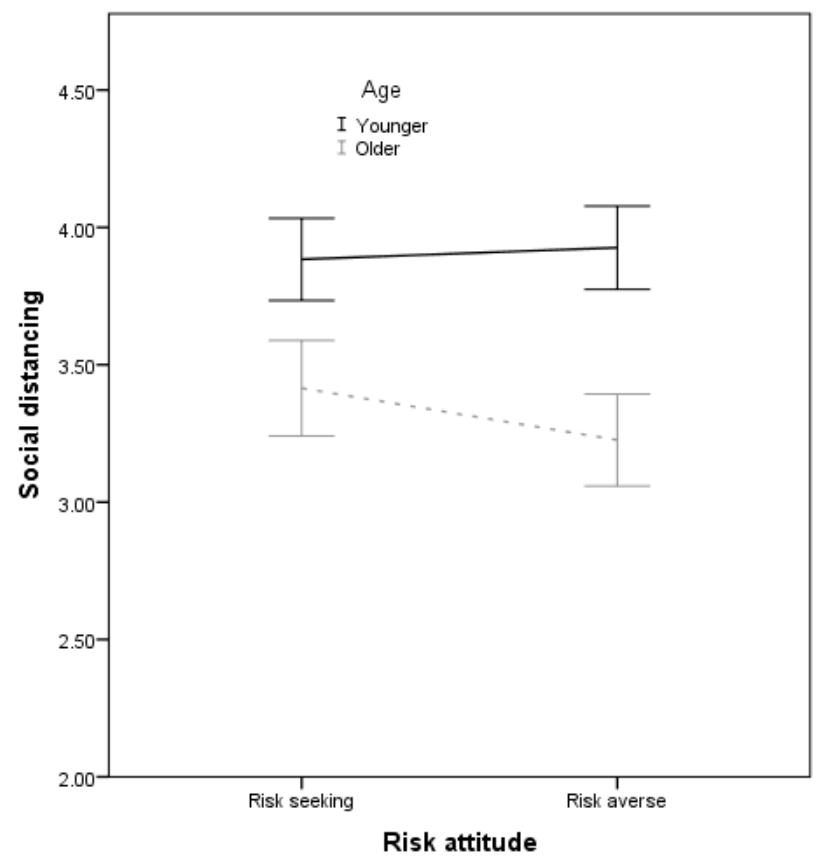

Figure 3. Interaction between risk attitude and age on social distancing. 


\section{Discussion}

The COVID-19 pandemic has been deadly, but health experts suggest there are certain behaviors that one can practice to reduce the spread of the virus i.e., social distancing and mask wearing (Leung et al., 2020). The manner in which these preventative-behavior messages are presented to the public may have an effect on how individuals respond to the message. There are also other psychological and demographic factors that may influence how or why individuals have responded to the pandemic with the use of protective behaviors in different ways. It is important to understand these factors in order to best communicate health-related messages to certain groups of people in order to gain the highest level of compliance.

The present study manipulated the number of projected deaths with gain-loss framing. A major finding was that in general, participants in the loss-framed condition (130,000 deaths without preventative measures) were more likely to wear a mask and follow social distancing than those in the gain-framed condition (130,000 lives could be saved with preventative measures). Such a pattern was consistent with the concept of loss aversion, which states that the negative feeling toward losses is stronger than the positive feeling toward equal amount gains (Tversky \& Kahneman, 1979). It is worth noting that with a similar manipulation, Sanders et al. (2021) did not find a significant framing effect on views on lockdown and intention to adhere to public health guidelines, whereas Gantiva et al. (2021) found the gain-framed message was more effective in promoting self-care behaviors. A possible reason could be timing and severity of the situation. When Gantiva et al. (2021) and Sanders et al. (2021) collected their data in April and May, 2020, respectively, there were approximately 5,000 COVID-19 cases and 250 deaths in Columbia, and 248,000 COVID-19 cases and 35,000 deaths in the U.K. (www.worldometers.info/coronavirus). The present study collected data on November $11^{\text {th }}$, 
2020. By this time, there had been over 9.2 million COVID-19 cases and 230,000 deaths in the U.S. Thus, the situation was far worse when the present study was performed even when taking the size of the population into account. As a result, U.S. residents might be more alarmed and horrified by the severity of the situation. Hence, they were more sensitive to the loss-framed message. Additionally, some past studies found that gain-framed messages were more effective in promoting health behaviors. For instance, Yang (2018) found gain-framed messages had a larger impact on smoking cessation. As noted in Rothman and Salovey (1997), the effectiveness of gain-loss framing was related to outcome uncertainty. Compared to gain-framed message, loss-framed message was more effective when the outcome was more uncertain. Consistent with this notion, because the effect of COVID-19 on illness and deaths was much more uncertain and less understood than the effect of smoking, loss-framed messages appeared to be more influential in the present study. Together, despite the differences, the present study still added to the body of knowledge about framing and health behaviors.

The present study also tested the role of three individual characteristics in protecting behaviors in the COVID-19 pandemic. Consistent with past research and a Gallup poll (Ritter, 2020; Xu \& Cheng, 2021), the present study replicated the role of political ideology, with more liberal ideology being associated with more preventative behaviors. Risk-averse attitude was positively related to mask-wearing but not social distancing. The study also found such an attitude interacted with age, with the effect of risk attitude being stronger in older adults. The difference in protecting behaviors between the two age groups might be due to the greater effects of the coronavirus on the older population. For instance, the rate of mortality was much higher in the elderly compared to individuals less than 50 years old (Kang \& Jung, 2020). Thus, older adults might take the risk more seriously and weigh risk more in their decisions. Additionally, 
the study found a positive relationship between subjective numeracy and mask-wearing, and thus supported the numeracy hypothesis regarding positive association between numeracy and advantageous decisions (Sinayev \& Peters, 2015).

More importantly, our study examined the potential moderating effect of these individual characteristics on framing and found a significant interaction between political ideology and framing on mask-wearing. Consistent with Thibodeau and Boroditsky (2011), we found conservatives, as opposed to liberals, were relatively insensitive to framing manipulation. Xu and Cheng (2021) also found that more conservative ideology weakened the effect of need for cognition and self-control on mask-wearing. A possible reason might be that conservatives held not only a more negative but also a firmer view on protecting behaviors in the pandemic, given that former President Trump and other conservative political figures repeatedly refuse to wear a mask and downplayed the usefulness of mask (Givhan, 2020; Kempthorne \& Terrizzi, 2021). Thus, people with a more conservative ideology might be less influenced by other factors, including message framing.

The present study generated some implications. First, message framing is a technique that can be used in a variety of domains of life. Framing has a large impact on how the audience perceives and responds to a message, and hence it is essentially a fast way to change behaviors. Consistent with this notion, the present study found a significant main effect of framing. Therefore, the government can use framing towards how they go about placing restrictions and mask-mandates.

Second, together with other studies (Kempthorne \& Terrizzi, 2021; Ramos et al., 2020; Xu \& Cheng, 2021), the present study demonstrated a profound influence of politics in the pandemic. It is noted that the 2020 United States presidential election took place during the midst 
of the COVID-19 pandemic, and it was one of the most intense and contrasting elections to date. While this was not a political study, the COVID-19 pandemic itself has been overly politicized by the media and political figures in the U.S. (Kahane, 2021), and our findings were consistent with the argument that politicization might have an effect on the public's health (Gostin, 2018). At this point, while specific means is not immediately clear given the partisan political climate in the U.S., the study still advocates for depoliticizing the pandemic and preventative measures. While wearing a mask and keeping social distancing are both preventative measures, results from the present study suggested they were related but different. Compared to social distancing, mask-wearing was subject to more intrinsic and extrinsic factors (risk attitude, subjective numeracy, and the interaction between framing and political ideology). A possible reason might be that social distancing was introduced before mask-wearing in the U.S. and residents were more used to social distancing. Alternatively, culture might be a reason because mask-wearing is relatively new to Western countries (Joung, 2020). Regardless of the reason, the findings imply that the government may need to spend more effort on introducing the benefits and necessity of wearing a mask.

Limitations should be addressed as well. First, the present study failed to find an interaction between subjective numeracy and framing. A possible reason for this might be that the numerical information in the framing messages (i.e., 130,000 lives saved/lost) was too easy to trigger the numeracy effect. Also, the present study did not adopt objective numeracy as a comparison. Thus, it was not clear whether the non-significant result was due to the difference between objective and subjective numeracy. Future research should adopt both to fully illustrate the function of numeracy in the pandemic. 
Second, the study's sample was not particularly racially/ethnically diverse. Although our study was not looking at the relationship between race and protective behavior compliance, it is important to gain a diverse sample in order to generalize the results to the public. Therefore, a further look into the relationship between race/ethnicity on the use of protective-related behaviors or on framing sensitivity would be beneficial and add to the literature.

In conclusion, the present study suggests that individuals who are more risk averse, liberal, and who have a higher subjective numeracy score will demonstrate higher levels of mask wearing or social distancing compliance. In addition, loss framing may be more influential in the promotion of health-related behaviors. Moreover, such a framing effect is more prominent in liberals than in conservatives. Overall, the present study depicts the function of framing in health communication and highlights the key psychological and demographic factors on the decision to use protective behaviors during the COVID-19 pandemic. 


\section{References}

Best, R., \& Charness, N. (2015). Age differences in the effect of framing on risky choice: A meta-analysis. Psychology and aging, 30(3), 688-698. https://doi.org/10.1037/a0039447

Blais, A.-R., \&amp; Weber, E. U. (2006). A domain-specific risk-taking (DOSPERT) scale for adult populations. Judgment and Decision Making, 1, 33-47.

Chan, H. F., Skali, A., Savage, D. A., Stadelmann, D., \& Torgler, B. (2020). Risk attitudes and human mobility during the COVID-19 pandemic. Scientific Reports, 10(1), 19931. https://doi.org/10.1038/s41598-020-76763-2

Cheng, J. (2020). The role of numeracy and impulsivity in intertemporal choice and decision making. Psychological Thought. 13. 254-272. 10.37708/psyct.v13i1.442.

De Witte, M. (2020). Why people didn't social distance. Retrieved from https://news.stanford.edu/2020/04/14/people-didnt-social-distance/

Fagerlin, A., Zikmund-Fisher, B. J., Ubel, P. A., Jankovic, A., Derry, H. A., \& Smith, D. M. (2007). Measuring Numeracy without a Math Test: Development of the Subjective Numeracy Scale. Medical Decision Making, 27(5), 672-680.

https://doi.org/10.1177/0272989X07304449

Fetter, D. S., Dharmar, M., Lawry-Hall, S., Pressman, J., Chapman, J., \& Scherr, R. E. (2019). The Influence of Gain-Framed and Loss-Framed Health Messages on Nutrition and Physical Activity Knowledge. Global Pediatric Health. $\underline{\text { https://doi.org/10.1177/2333794X19857405 }}$

Gantiva, C., Jiménez-Leal, W., \& Urriago-Rayo, J. (2021). Framing Messages to Deal With the COVID-19 Crisis: The Role of Loss/Gain Frames and Content. Frontiers in psychology, 12, 568212. https://doi.org/10.3389/fpsyg.2021.568212 
Givhan, R. (2020). Perspective | Trump's refusal to wear face masks turned them into a sad national symbol. Retrieved from https://www.washingtonpost.com/nation/2020/10/03/trumps-refusal-wear-face-masksturned-them-into-sad-national-symbol/

Gostin LO. (2018). Language, Science, and Politics: The Politicization of Public Health. JAMA. 319(6):541-542. doi:10.1001/jama.2017.21763

Hameleers, M. (2020). Prospect Theory in Times of a Pandemic: The Effects of Gain versus Loss Framing on Policy Preferences and Emotional Responses During the 2020 Coronavirus Outbreak. https://doi.org/10.31235/osf.io/7pykj

Holton, A., Lee, N., \& Coleman, R. (2014). Commenting on Health: A Framing Analysis of User Comments in Response to Health Articles Online. Journal of Health Communication, 19(7), 825-837. doi:10.1080/10810730.2013.837554

IHME: COVID-19 projections. (2020). Retrieved from https://covid19.healthdata.org/global?view=total-deaths\&tab=trend

Inbar, Y., \& Lammers, J. (2012). Political diversity in social and personality psychology. Perspectives on Psychological Science, 7, 496-503. doi:10.2139/ssrn.2002636

Jennings, S. (2020). COVID-19 Update: US and Global Cases, deaths, and recoveries as of November 3, 2020. Retrieved from https://www.patientcareonline.com/view/covid-19update-us-and-global-cases-deaths-and-recoveries-as-of-november-3-2020

Jordan, J., Yoeli, E., \& Rand, D. G. (2020). Don't get it or don't spread it? Comparing selfinterested versus prosocial motivations for COVID-19 prevention behaviors. https://doi.org/10.31234/osf.io/yuq7x 
Joung, M. (2020). Face mask culture common in east, new to west. VOANEWS. Retrieved from https://www.voanews.com/science-health/coronavirus-outbreak/face-mask-culturecommon-east-new-west

Kahane L. H. (2021). Politicizing the Mask: Political, Economic and Demographic Factors Affecting Mask Wearing Behavior in the USA. Eastern economic journal, 1-21. Advance online publication. https://doi.org/10.1057/s41302-020-00186-0

Kang, S. J., \& Jung, S. I. (2020). Age-Related Morbidity and Mortality among Patients with COVID-19. Infection \& chemotherapy, 52(2), 154-164.

\section{https://doi.org/10.3947/ic.2020.52.2.154}

Kempthorne, J. C., \& Terrizzi, J. A., Jr (2021). The Behavioral Immune System and Conservatism as Predictors of Disease-Avoidant Attitudes During the COVID-19 Pandemic. Personality and individual differences, 110857. Advance online publication. https://doi.org/10.1016/j.paid.2021.110857

Leung, C. C., Cheng, K. K., Lam, T. H., \& Migliori, G. B. (2020). Mask wearing to complement social distancing and save lives during COVID-19. The International Journal of Tuberculosis and Lung Disease, 24(6), 556-558. doi:10.5588/ijtld.20.0244

Luo, J. M., \& Lam, C. F. (2020). Travel Anxiety, Risk Attitude and Travel Intentions towards “Travel Bubble” Destinations in Hong Kong: Effect of the Fear of COVID-19. International Journal of Environmental Research and Public Health, 17(21). https://doi.org/10.3390/ijerph17217859

Mather, M., Mazar, N., Gorlick, M. A., Lighthall, N. R., Burgeno, J., Schoeke, A., \& Ariely, D. (2012). Risk preferences and aging: the "certainty effect" in older adults' decision making. Psychology and aging, 27(4), 801-816. https://doi.org/10.1037/a0030174 
Miguel, F. K., Machado, G. M., Pianowski, G., \& Carvalho, L. de F. (2021). Compliance with containment measures to the COVID-19 pandemic over time: Do antisocial traits matter? Personality and Individual Differences, 168, 110346. https://doi.org/10.1016/j.paid.2020.110346

Ogbodo, J. N., Onwe, E. C., Chukwu, J., Nwasum, C. J., Nwakpu, E. S., Nwankwo, S. U., Nwamini, S., Elem, S., \& Iroabuchi Ogbaeja, N. (2020). Communicating health crisis: a content analysis of global media framing of COVID-19. Health promotion perspectives, 10(3), 257-269. https://doi.org/10.34172/hpp.2020.40

Centers for Disease Control and Prevention. (2021). Older adults and COVID-19. Retrieved from https://www.cdc.gov/coronavirus/2019-ncov/need-extra-precautions/olderadults.html\#: : text=Help\%20at\%20Home,The $\% 20$ risk $\% 20$ for\%20severe\%20illness\%20with\%20COVID\%2D19\%20increases\%20 with,than\%20people\%20in\%20their\%2050s.

Palm, R., Bolsen, T., \& Kingsland, J. (2021). The Effect of Frames on COVID-19 Vaccine Hesitancy. medRxiv. https://doi.org/10.1101/2021.01.04.21249241

Peters, E. (2012). Beyond Comprehension: The Role of Numeracy in Judgments and Decisions. Current Directions in Psychological Science, 21(1), 31-35. https://doi.org/10.1177/0963721411429960

Peters, E., \& Bjalkebring, P. (2015). Multiple numeric competencies: When a number is not just a number. Journal of personality and social psychology, 108(5), 802-822. https://doi.org/10.1037/pspp0000019 
Peters, E., \& Levin, I. P. (2008). Dissecting the risky-choice framing effect: Numeracy as an individual-difference factor in weighting risky and riskless options. Judgment and Decision Making, 3(6), 435-448.

Pham, C. \& Cheng, J. (2020). Perceptions of the Police: The Role of Need for Cognition and Numeracy. Studia Psychologica. 62. 314-334. 10.31577/sp.2020.04.807.

Ramos, G., Vieites, Y., Jacob, J., \& Andrade, E. B. (2020). Political orientation and support for social distancing during the COVID-19 pandemic: evidence from Brazil. Revista de Administração Pública, 54(4), 697-713. https://doi.org/10.1590/0034-761220200162x

Reyna, V. F., Nelson, W. L., Han, P. K., \& Dieckmann, N. F. (2009). How numeracy influences risk comprehension and medical decision making. Psychological bulletin, 135(6), 943973. https://doi.org/10.1037/a0017327

Ritter, Z. (2020). Republicans Still Skeptical of COVID-19 Lethality. Retrieved from https://news.gallup.com/poll/311408/republicans-skeptical-covid-lethality.aspx

Rothman, A. J., \& Salovey, P. (1997). Shaping perceptions to motivate healthy behavior: The role of message framing. Psychological Bulletin, 121(1), 3-19. https://doi.org/10.1037/0033-2909.121.1.3

Sanders, M., Stockdale, E., Hume, S., \& John, P. (2021). Loss aversion fails to replicate in the coronavirus pandemic: Evidence from an online experiment. Economics letters, 199, 109433. https://doi.org/10.1016/j.econlet.2020.109433

Sikali K. (2020). The dangers of social distancing: How COVID-19 can reshape our social experience. Journal of community psychology, 48(8), 24352438. https://doi.org/10.1002/jcop.22430 
Shah, S., \& Farrow, A. (2020). A commentary on "World Health Organization declares global emergency: A review of the 2019 novel Coronavirus (COVID-19)". International journal of surgery (London, England), 76, 128-129. https://doi.org/10.1016/j.ijsu.2020.03.001

Sinayev, A., \& Peters, E. (2015). Cognitive reflection vs. calculation in decision making. Frontiers in psychology, 6, 532. https://doi.org/10.3389/fpsyg.2015.00532

Tabesh, P., Tabesh, P., \& Moghaddam, K. (2019). Individual and contextual influences on framing effect: Evidence from the Middle East. Journal of General Management, 45(1), 30-39. https://doi.org/10.1177/0306307019851337

Thibodeau, P. \& Boroditsky, L. (2011). Metaphors We Think With: The Role of Metaphor in Reasoning. PloS one. 6. e16782. 10.1371/journal.pone.0016782.

Tversky, A. \& Kahneman, D. (1979). Prospect Theory: An Analysis of Decision under Risk. Econometrica, 47(2), 263-291. doi:10.2307/1914185

Tversky, A., \& Kahneman, D. (1981). The framing of decisions and the psychology of choice. Science, 211(4481), 453-458. doi:10.1126/science.7455683

Whyte, S., Lau E., Nissen, L. \& Torgler, B. (2017). You should know better! Do health students have different risk attitudes to unplanned pregnancy and sexually transmitted diseases?, Applied Economics Letters, 24:21, 1526-1532, DOI: 10.1080/13504851.2017.1305085

Xie, W., Campbell, S., \& Zhang, W. (2020). Working Memory Capacity Predicts Individual Differences in Social Distancing Compliance during the COVID-19 Pandemic in the U.S. PNAS, 117(30), 17667-17674

$\mathrm{Xu}, \mathrm{P} .$, \& Cheng, J. (2021). Individual differences in social distancing and mask-wearing in the pandemic of COVID-19: The role of need for cognition, self-control and risk attitude. 
Personality and individual differences, 175, 110706.

https://doi.org/10.1016/j.paid.2021.110706

Yang, D.-J. (2018). Exploratory Neural Reactions to Framed Advertisement Messages of Smoking Cessation. Social Marketing Quarterly, 24(3), 216-232.

https://doi.org/10.1177/1524500418788306 